\title{
Innovative Biocontrolling Method of Dengue Fever Vector, Aedes aegypti (Diptera: Culicidae)
}

\author{
Mohamed H. Madkour ${ }^{1}$, Ahmed A. Zaitoun ${ }^{2} \&$ Fatma A. Singer ${ }^{3}$ \\ ${ }^{1}$ Environmental sciences Dept., Faculty of Meteorology, Environment and Arid Land Agriculture, King Abdulaziz \\ Univ., Jeddah, Saudi Arabia \\ ${ }^{2}$ Arid Land Agriculture sciences Dept., Faculty of Meteorology, Environment and Arid Land Agriculture, King \\ Abdulaziz Univ., Jeddah, Saudi Arabia \\ ${ }^{3}$ Deanship for Accommodation and Nutrition, Girls Section, King Abdulaziz Univ., Jeddah, Saudi Arabia \\ Correspondence: Mohamed H. Madkour, Environmental sciences Dept., Faculty of Meteorology, Environment \\ and Arid Land Agriculture, King Abdulaziz Univ., Jeddah, Saudi Arabia. Tel: 966-532-690-171. E-mail: \\ madkour55@yahoo.com
}

Received: June 3, 2014 Accepted: July 3, 2014 Online Published: August 15, 2014

doi:10.5539/jas.v6n9p208 URL: http://dx.doi.org/10.5539/jas.v6n9p208

\begin{abstract}
The control of mosquitoes is an important public health concern around the world. The activity of petroleum ether extracts of Dodonaea viscose, Lantana camara and Ruta chaliphenses have been investigated towards larval development of Aedes aegypti. The plant extracts exhibits variable biological activity against Ae. aegypti. The greatest effect was observed with Dodonaea viscose and Lantana camara. They showed acute $\mathrm{LC}_{50}$ (2days) of 126.2, 136.9 and chronic $\mathrm{LC}_{50}$ (10 days) of 64.6 and $68.5 \mathrm{ppm}$, respectively. Larvae suffered chronic toxicities leading to $97.8 \%$ mortality using Dodonaea viscose and $95.6 \%$ using Lantana camara. Egg hatchability was significantly reduced in Dodonaea viscose and Lantana camara concentrations. All extracts concentrations of Dodonaea viscose and Lantana camara as well as higher extract concentration of Ruta chaliphenses caused significant high hindrance of subsequent larval development and consequently reduced both pupation and adult mergence. Drastic retardation of development was shown using Dodonaea viscose extracts $(17.3,7.4 \%)$ and Lantana camara extracts $(19.3,9.0 \%)$ from larval stage managed to pupal and adult stages, when reared in very low concentration (100 ppm) of the extracts. Ruta chaliphense was only more effective at higher concentrations. Hence, application of these extracts to Ae. aegypti mosquito breeding sites can be used as an innovative valuable alternative to the existing synthetic pesticides for the control of Ae. aegypti.
\end{abstract}

Keywords: petroleum ether extraction, toxicity, Aedes aegypti, Dodonaea viscose, Lantana camara and Ruta chaliphenses

\section{Introduction}

Insect transmitted diseases remain a major source of illness and death worldwide. Mosquitoes are still the world's number one vectors of human and animal diseases. These diseases including malaria, filariasis, yellow and dengue fever and Japanese encephalitis, contribute significantly to poverty and social debility in tropical countries (Jang, Kim, Ahn, \& Lee, 2002; Rajkumar \& Jebanesan, 2005). Aedes aegypti, the main carrier for viruses that cause dengue and dengue hemorrhagic and yellow fevers, is found majorly in the tropics and subtropics (Langat et al., 2012). There is no effective vaccine against dengue, and thus the only way of significantly lowering the incidence of this disease is through mosquito control (Malavige, Fernando, Fernando, \& Seneviratne, 2004). The target of mosquito control is to prevent proliferation of mosquito borne diseases and to improve quality of environment and public health. Mosquitoes are conspicuous nuisance pests as well, even after massive efforts of eradication or control (El-Maghraby, Nawwar, Bakr, Helmy, \& Kamel, 2012). The extensive use of chemical pesticides or insecticides resulted in inducing resistance by insect pests besides, residue contamination of human food, mammalian toxicity and environmental pollution (Domingues, Agra, Monaghan, Soares, \& Nogueira, 2010). One alternative approach is the use of insecticides from natural origin, especially plant-derived products to resolve these problems (Elhag, Harraz, Zaitoun, \& Salama, 1996). Several studies have emphasized the importance of research and development of herbal substances for controlling mosquitoes (Shaalan, Canyon, Younes, Abdel-Wahab, 2012). Sukumar, Perich, and Boobar (1991) listed and 
discussed results of 344 plant species that only exhibited mosquitocidal activity. The phytochemicals derived plant recourses can act as larvicides, insect growth regulators, repellant and ovipositional attractant (Das, Baruah, Talukadar, \& Das, 2003; Venkatachalam \& Jebanesan, 2001). Extracts of onion, garlic, eucalyptus and tobacco are reported to control many plant pathogenic fungi and insects. The neem biopesticides is usually used for all biological materials and organisms, which can be formulated for use as pesticides for the control of pests (Praveena, Venkatasubbu, \& Jegadeesan, 2012). Kumar, Dhamodaran, Nilani, and Balakrishnan (2012) found that the hole extracts of Tephrosia purpurea (L.) has larvicidal activity against the larvae of Culex quinquefasiciatus. The three plants of Dodonea viscose, Lantana camara and Ruta chalepensis are available in Saudi Arabia and used in folk medicine (Migahid, 1978). Mogahed and Gesraha (2005) found that the extract of Dodonea viscosa significantly reduced the infestation of cotton plant by many insect pests. Also, Lantana camara and Ruta chalipenesis were tested for their efficacy against parasitic bee mite, Varroa destructor and toxic effect against the mite (Zaitoun \& Madkour, 2012).

Therefore, the main objective of the present study was to investigate the effect of petroleum ether extracts from three plant species: Dodonea viscosa, Lantana camara and Ruta chalipensis on egg hatchability and larval development in Aedes aegypti mosquitoes.

\section{Materials and Methods}

\subsection{Insects}

The mosquito Ae. Aegypti, larvae was collected from the natural sites located in Jeddah city, Saudi Arabia. Colonies were maintained in the laboratory. Mosquitoes were held at $27 \pm 1{ }^{\circ} \mathrm{C}, 70 \pm 5 \% \mathrm{RH}$, and photo regime of 14:10 h (light: dark). Adults were provided with a $10 \%$ sucrose solution as food source. Female mosquitoes were allowed to blood feed periodically from pigeon host. Larvae were reared in dechlorinated water under the same laboratory conditions and were fed with fish food. The experiments were carried out at the Faculty of Meteorology, Environment and Arid Land Agriculture, King Abdulaziz University, Jeddah, Saudi Arabia.

\subsection{Plant Collection and Extractions}

Test materials, Dodonaea viscose, Lantana camara and Ruta chaliphenses were collected from different parts of Saudi Arabia, and were authenticated by a specialist from Faculty of Pharmacy, King Abdulaziz University, Saudi Arabia. Plant leafs were air dried in the laboratory, ground in a mortar and extracted with petroleum ether. One hundred grams of powder for each solvent separately were extracted three times with $300 \mathrm{ml}$ of petroleum ether at room temperature. After $24 \mathrm{~h}$, the supernatants were decanted, filtrated through filter paper and dried in a rotary evaporator to obtain a semi solid crude extract according to Chitra, Janardhan, Kameswara, and Nagaiah (1993). The dry extracts were kept in refrigerator until using for experiments.

\subsection{Test Procedure}

Stock solution of the three plant petroleum ether extracts were prepared by dissolving the dry extract in warm distilled $\mathrm{H}_{2} \mathrm{O}\left(0.5 \mathrm{~g} / 100 \mathrm{~mL} \mathrm{H}_{2} \mathrm{O}\right)$. Two drops of Tween. 80 as emulsifier were used to facilitate the dissolving of tested material in water. Different concentration of 100, 200, 300, 400 and $500 \mathrm{ppm}$ were prepared from the stock solution. About 30 freshly laid eggs or 30 second instars larvae were transferred from the culture into plastic cups (8-cm diameter, $10 \mathrm{~cm}$ deep), each containing $30 \mathrm{ml}$ of the desired concentration. Treatments were carried out in triplicate and control larvae received only 2 drop of Tween. 80 in distilled water. Larvae were fed adlibitum and kept under laboratory conditions. Larval mortalities were counted at 2, 4 and 10 days after treatment. Percentage of successful pupation and adult emergence were determined by monitoring on daily basis until all adults in the control have emerged.

Data were analyzed using maximum likelihood procedures and the effectiveness was expressed as $\mathrm{LC}_{50}$ values according to Finney (1971). Data were corrected for control mortality (Abbot, 1925). Egg hatchability data were analyzed by an analysis of variance. If significant differences $(\mathrm{p}<0.05)$ occurred, means were separated by Duncan's multiple range test.

\section{Results and Discussion}

Data given in table (1) indicated the biological activity of petroleum ether extracts of Dodonaea viscose, Lantana camara and Ruta chalepensis against the $2^{\text {rd }}$ instar larvae of Ae. aegypti. The mortality percentages of Ae. aegypti larvae, their $\mathrm{LC}_{50}$ values and $95 \%$ confidence limits at 2, 4, 10 days after treatment are shown in Table 1, 2. Data shows that 97.8 and $95.6 \%$ mortality of larvae reached after 10 days of exposure to $500 \mathrm{ppm}$ of $D$. viscose and L.camara extracts, respectively. However, the lowest $D$. viscose concentration (100 ppm) caused $47.8 \%$ mortality after 2 days of treatment. Ruta chalepensis petroleum ether extract caused the lowest mortalities, whereas highest concentration (500 ppm) caused $84.4 \%$ mortality after 10 days of treatment compared to $3.3 \%$ 
for the controls. Data of Table 2 showed significant differences. $\mathrm{LC}_{50}$ for second instars larvae were (126.18 and 64.56), (136.89 and 68.49) and (173.66 and 75.43) for Dodonaea viscose, Lantana camara and Ruta chalepensis, respectively after 2 and 10 days from exposure of larvae to plant extracts. Dodonaea viscose and Lantana camara were significantly more toxic at all exposure times than Ruta chalepensis.

Table 1. Effect of plant extract on the mortality percentages of larvae of Aedes aegypti

\begin{tabular}{|c|c|c|c|c|}
\hline \multirow{2}{*}{ Plant Extract } & \multirow{2}{*}{ Conc. (ppm) } & \multicolumn{3}{|c|}{ \% Mortality after } \\
\hline & & $2^{\text {nd }}$ day & $4^{\text {th }}$ day & $10^{\text {th }}$ day \\
\hline \multirow{6}{*}{ Dodonaea viscosa } & 100 & 47.8 & 52.2 & 66.7 \\
\hline & 200 & 56.7 & 67.8 & 77.8 \\
\hline & 300 & 70.0 & 73.3 & 84.4 \\
\hline & 400 & 81.1 & 85.6 & 92.2 \\
\hline & 500 & 90.0 & 94.4 & 97.8 \\
\hline & control & 00.0 & 00.0 & 03.33 \\
\hline \multirow{6}{*}{ Lantana camara } & 100 & 45.6 & 51.1 & 65.6 \\
\hline & 200 & 54.7 & 68.9 & 74.4 \\
\hline & 300 & 67.8 & 71.1 & 81.1 \\
\hline & 400 & 80.0 & 83.4 & 91.1 \\
\hline & 500 & 85.6 & 93.3 & 95.6 \\
\hline & Control & 00.0 & 00.0 & 06.7 \\
\hline \multirow{6}{*}{ Ruta chalepensis } & 100 & 41.1 & 45.6 & 60.0 \\
\hline & 200 & 46.7 & 62.2 & 66.7 \\
\hline & 300 & 61.1 & 67.8 & 76.7 \\
\hline & 400 & 71.1 & 75.8 & 81.3 \\
\hline & 500 & 75.6 & 81.1 & 84.4 \\
\hline & Control & 00.0 & 00.0 & 03.0 \\
\hline
\end{tabular}

Table 2. $\mathrm{LC}_{50}$ values and $95 \%$ confidence limits of Aedes aegypti larvae in media containing petroleum ether plant extracts

\begin{tabular}{cccc}
\hline Plant material & Assay time (days) & Slope & $\mathbf{L C}_{\mathbf{5 0}} \mathbf{( 9 5 \% \mathbf { C L } )}$ \\
\hline \multirow{3}{*}{ Dodonaea viscosa } & 2 & 1.64 & $126.18(96.55-164.68)$ \\
& 4 & 1.83 & $104.25(78.57-138.13)$ \\
& 10 & 1.78 & $64.56(41.84-99.30)$ \\
\hline \multirow{3}{*}{ Lantana camara } & 2 & 1.66 & $136.89(106.94-175.63)$ \\
& 4 & 1.76 & $105.31(78.70-140.69)$ \\
Ruta chalepensis & 10 & 1.62 & $68.49(41.08-104.04)$ \\
& 2 & 1.37 & $173.66(136.08-221.39)$ \\
& 4 & 1.40 & $123.40(89.67-169.52)$ \\
& 10 & 1.19 & $75.43(45.55-142.42)$ \\
\hline
\end{tabular}

Egg hatchability was significantly lower $(\mathrm{p}<0.05)$ in all extracts than control (Table 3). At $100 \mathrm{ppm}$ concentration, Dodonaea viscose and Lantana camara had the most sever effect on egg hatching rate which were reduced by about $35 \%$ and $33.5 \%$ compared with $26 \%$ for Ruta chalepensis. At their highest concentration (500 ppm), the tree plant extract reduced egg hatchability percentages by about $90 \%, 87 \%$ and $69 \%$ for Dodonaea 
viscose, Lantana camara and Ruta chalepensis respectively. In fact, about $90 \%$ of the emerging larvae died within the first 2 days in the Dodonaea viscose extract at this concentration.

Table 3. Egg hatchability percentages of Aedes aegypti in media containing plant extracts

\begin{tabular}{ccc}
\hline Plant extract & Concentration(ppm) & Mean\% Egg Hatchability* \\
\hline \multirow{3}{*}{ Dodonaea viscosa } & 100 & $65.0 \mathrm{~cd}$ \\
& 200 & $52.6 \mathrm{e}$ \\
& 300 & $45.7 \mathrm{f}$ \\
Lantana camara & 400 & $22.5 \mathrm{i}$ \\
& 500 & $10.3 \mathrm{j}$ \\
\hline \multirow{2}{*}{ Ruta chalepensis } & 100 & $66.5 \mathrm{c}$ \\
& 200 & $54.9 \mathrm{e}$ \\
& 300 & $47.2 \mathrm{f}$ \\
& 400 & $26.7 \mathrm{i}$ \\
& 500 & $13.0 \mathrm{j}$ \\
\hline & 100 & $73.7 \mathrm{~b}$ \\
& 200 & $61.3 \mathrm{~d}$ \\
& 300 & $53.9 \mathrm{e}$ \\
& 400 & $40.6 \mathrm{~g}$ \\
& 500 & $97.2 \mathrm{~h}$
\end{tabular}

*Means followed by the same letter are not significantly different at $5 \%$ level, Duncan's multiple tests.

On the other hand all plant extracts had an evidence inhibitory effect even at their lowest concentrations (100 ppm), where the successful pupation were only 17.3, 19.3 and 39.3 for Dodonaea viscose, Lantana camara and Ruta chalepensis, respectively. Complete suppression of adult emerging was evident in the $500 \mathrm{ppm}$ concentration of Dodonaea viscose and Lantana camara. The adult emerging percentages from the $100 \mathrm{ppm}$ treatments were 7.4, 9.0 and 14.9 for Dodonaea viscose, Lantana camara and Ruta chalepensis, respectively (Table 4).

Table 4. Successful pupation and adult emergence of Aedes aegypti larvae reared in media containing plant extracts

\begin{tabular}{cccc}
\hline \multirow{2}{*}{ Plant extract } & \multirow{2}{*}{ Conc. $(\mathbf{p p m})$} & \multicolumn{2}{c}{$\%$ Successful pupation or adult emergence } \\
\cline { 3 - 4 } & & Pupation & Adult emergence \\
\hline \multirow{4}{*}{ Dodonaea viscosa } & 100 & 17.3 & 7.4 \\
& 200 & 12.2 & 3.7 \\
& 300 & 6.1 & 2.2 \\
& 400 & 1.1 & 0.0 \\
Lantana camara & 500 & 0.0 & 0.0 \\
\hline \multirow{5}{*}{ Ruta chalepensis } & 100 & 19.3 & 9.0 \\
& 200 & 15.7 & 7.1 \\
& 300 & 8.4 & 5.3 \\
& 400 & 5.1 & 2.2 \\
& 500 & 0.0 & 0.0 \\
\hline \multirow{5}{*}{} & 100 & 39.3 & 14.9 \\
& 200 & 23.9 & 10.3 \\
& 300 & 14.3 & 7.5 \\
& 400 & 8.7 & 3.7 \\
& 500 & 2.1 & 0.0 \\
\hline
\end{tabular}


Considerable biological activity related to toxicity and hindrance of growth and development of the larvae of $A e$. aegypti has been observed with the petroleum ether extracts of the three plant materials investigated. Of the three plant extracts, Dodonaea viscose and Lantana camara were found to cause higher rate of mortality compared with Ruta chalepensis. Thus, the extract of Dodonaea viscose caused toxicity at $300 \mathrm{ppm}$ concentration leading up to $70 \%$ larval mortality over a period of 48 hrours, and $84.4 \%$ mortality after exposure for 10 days. Praveena, Venkatasubbu and Jegadeesan (2012) found that Dodonaea viscose extract has antifeedant acivity against spotted bollworm. Also, Zaitoun and Madkour (2012) found that L. camara extract was very effective against Varroa destructor. Emam, Swelam, and Megally (2009) found that furocoumarin and quinolone alkaloid isolated from Ruta chalepensis, showed larvicidal and antifeedant activity against the cotton pest, Spodoptera littoralis larvae.

\section{Conclusions}

The results obtained in this study demonstrated the importance, the toxic, growth and development-retarding influence of the extracted plant materials, especially Dodonaea viscose and Lantana camara on Ae. aegypti mosquitoes. It is anticipated that such effects may be observable when these materials are applied in natural larval breeding habitats in rural as well as in urban localities. Moreover, application of these materials is not likely to leave harmful residues in the environment science they are naturally occurring among the local flora.

\section{Acknowledgements}

This project was funding by the Deanship of Scientific Research (DSR), King Abdulaziz University, Jeddah under grant no. 217-155-1433. The authors, therefore, acknowledge with thanks DSR technical and financial support.

\section{References}

Abbot, W. S. (1925). A method of computing the effectiveness of an insecticide. J. Econ. Entomol., 18, 265-267.

Chitra, K. C., Janardhan, R., Kameswara, R., \& Nagaiah, K. (1993). Field evaluation of certain plant products in the control of brinial pest complex. Indian J. Entoml., 55(3), 237-240.

Das, N. G., Baruah, I., Talukadar, P. K., \& Das, S. C. (2003). Evaluation of botanicals as repellents against mosquitoes. J. Vec. Borne Dis., 40(1-2), 49-53. Retrieved from http://www.ncbi.nlm.nih.gov/pubmed/15119071

Domingues I, Agra, A. R., Monaghan, K., Soares, A. M., \& Nogueira, A. J. (2010). Cholinesterase and glutathione-S-transferase activities in freshwater invertebrates as biomarkers to assess pesticide contamination. Environ. Toxicol. Chem., 29, 5-18. http://dx.doi.org/10.1002/etc.23

Elhag, E. A., Harraz, F. M., Zaitoun, A. A., \& Salama, A. K. (1996). Evaluation of some wiled herb extracts for control of mosquitoes. J. King Saud Univ., Agric. Sci., 8, 135-1450.

El-Maghraby, S., Nawwar, G. A., Bakr, R. F. A., Helmy, N., \& Kamel, O. M. (2012). Toxicological studies for some agricultural waste extracts on mosquito larvae and experimental animals. Asian Paci. J. Trop. Biomed., 2(7), 558-563. http://dx.doi.org/10.1016/S2221-1691(12)60097-5

Emam, A. M., Swelam, E. S., \& Megally, N. Y. (2009). Furocoumarin and quinolone alkaloid with larvicidal and antifeedantActivities isolated from Ruta chalepensis Leaves. J. Nat. Prod., 2, 10-22.

Finney, D. J. (1971). Probit analysis (3rd edition). Cambridge: Cambridge University Pres.

Jang, Y. S., Kim, M. K., Ahn, Y. J., \& Lee, H. S. (2002). Larvicidal activity of Brazilian plants against Aedes aegypti and Culex pipiens pallens (Diptera: Culicidae). Agric. Chem. Biotechnol., 45(3), 131-134.

Kumar, D., Dhamodaran, P., Nilani, P., \& Balakrishnan, N. (2012). Larvicidal activity of Tephrosia purpurea (L.) against the larvae of Culex quinquefasiciatus. J. Appl. Pharm. Sci., 2(7), 219-221. http://dx.doi.org/10.7324/JAPS.2012.2735

Langat, B. K., Siele, D. K., Wainaina, C., Mwandawiro, C., Ondicho, J., Tonui, W. K., .. Mutai, C. K. (2012). Larvicidal effect of Mundulea sericea (Leguminosaea) plant extract against Aedes aegypti (L.) (Diptera: Culicidae). Afr. J. Pharmacol. Ther., 1(3), 106-109. Retrieved from http://www.uonbi.ac.ke/journals/kesobap/

Malavige, G. N., Fernando, S., Fernando, D. J., \& Seneviratne, S. L. (2004). Dengue viral infections. Postgrad. Med. J., 80(948), 588-601. http://dx.doi.org/10.1136/pgmj.2004.019638

Migahid, A. M. (1978). Flora of Saudi Arabia. University Press, Riyadh, Saudi Arabia.

Mogahed, M. I., \& Gesraha, M. A. (2005). Efficacy of Dodonaea viscosa plant extract on some insect pests 
infesting cotton plants under field conditions. Annals Agric. Sci. (Cairo), 50(2), 739-747.

Praveena, R., Venkatasubbu, G. D., \& Jegadeesan, M. (2012). Antifeedant activity of selected medicinal plants on Earias vittella. J. Biopest., 5(2), 96-99. Retrieved from http://www.jbiopest.com/users/LW8/efiles/Vol_5_2_96-99-12011.pdf

Rajkumar, S., \& jebanesan, A. (2005). Oviposition deternt and skin repellent activities of Solanum trilobatum leaf extract against the malarial vector Anopheles stephensi. J. Insect Sci., 5, 1-3. http://dx.doi.org/10.1672/1536-2442(2005)005[0001:ODASRA]2.0.CO;2

Shaalan, E. A. S., Canyon, D. E., Younes, M. W. F., \& Abdel-Wahab, H. (2012). Plant extracts as potential mosquito larvicides. Indian J. Med Res., 135(5), 581-598.

Sukumar, K, M., Perich, J., \& Boobar, L. R. (1991). Botanical derivatives in mosquito control: a review. J Am Mosq Control Assoc., 7(2), 210-37.

Venkatachalam, M. R., \& Jenbanesan, J. (2001). Larvicidal activity of Hydrocotyle japonica Thumb. (Rutacae) extract against Culex quinquefasciatus. Journal Experimental Zoology, 4(1), 99-101.

Zaitoun, A. A., \& Madkour, M. H. (2012). Acaricidal activity of some plant extracts on parasitic bee mite, Varroa destructor. J. Food. Agric. \& Environ., 10(3\&4), 1153-1155. Retrieved from http://world-food.net/acaricidal-activity-of-some-plant-extracts-on-parasitic-bee-mite-varroa-destructor/

\section{Copyrights}

Copyright for this article is retained by the author(s), with first publication rights granted to the journal.

This is an open-access article distributed under the terms and conditions of the Creative Commons Attribution license (http://creativecommons.org/licenses/by/3.0/). 